\section{Remote consultations and patient images: actual pitfalls in virtual practice}

\author{
Robert Wheeler
}

The High Court recently provided what appear to be the first judicial comments on remote consultations. These resonate with these two papers. ${ }^{12}$ The case ${ }^{3}$ concerned whether Mental Health Act 1983 (MHA) applications for assessment and treatment required face-to-face interview and examination. The court concluded that the MHA requires physical attendance of the practitioner on the patient. Although this decision is applicable only to clinical practice in England and Wales, the allure of virtual consultation will be felt throughout a world enduring a pandemic.

While the case was primarily concerned with mental illness, the management of which is highly prescribed in ways unfamiliar to doctors looking after the physical health of children, it nonetheless touched on the limitations of remote consultations applicable to us all. The notion of being unable to discern non-verbal cues such as the smell associated with poor hygiene, or to assess proprioception, or to notice tremor or the scars of self-harm was brought out in the judgement. More far-reaching concerns such as establishing the identity of the ostensible child patient, and the presence and influence of an adult in the same room of whom the doctor is oblivious, were not touched on, nor the idea that without notice the consultation may be recorded by the adult presenting the child. Whether or not the patient is, unbeknownst to the doctor, abroad may have considerable bearing on whether it is permissible to prescribe and on whether medical indemnity will be valid. Any negative influence on the consultation that the clinician would usually be alerted to and in control of in a clinic room may potentially become an uncontrolled variable in these circumstances.

There is no doubt that in the correct context, great and multifarious benefits can be derived from remote consultations, ${ }^{2}$ and the General Medical Council (GMC) has provided supportive guidelines. These are timely, with persuasive argument emerging identifying child patients as ideal recipients

Paediatric Surgery, Southampton University Hospitals NHS Trust, Southampton, UK

Correspondence to Dr Robert Wheeler, Paediatric Surgery, Southampton University Hospitals NHS Trust, Southampton SO 16 6YD, UK; robert.wheeler@uhs.nhs.uk of digital healthcare given their status as 'digital natives'. ${ }^{1}$ But this guidance does not address all of the concerns that the lack of physical examination poses for paediatricians. ${ }^{4}$ In addition, bearing in mind that the GMC advice on recording images was predicated on the physical attendance of the patient, one wonders whether the recording of virtual consultations is adequately served by this advice fully to account for the absence of the doctor in the room. Taken together with the judgement in Devon, the GMC's advice indicates how a reasonable standard of care for outpatient consultation, virtual or actual, might now be construed.

Considering a separate but allied entity, while the video element of remote consultations can make a powerful contribution to the success of the clinical encounter, parents often independently provide, at their own behest, images of their children for clinical purposes, another aspect of 'virtual' practice. These have for many years assisted us in the outpatients when assessing a child, particularly if the parents have taken a series of pictures documenting the evolution of a lump or rash or asymmetry. If of good quality, this contemporaneous visual record may reveal the history of an illness or anomaly in a fashion unmatchable by an oral report. Images can therefore be immensely helpful, not least in confirming a diagnosis which would otherwise necessitate a journey to the clinic, at which ironically the clinical problem may become temporarily invisible, such as an inguinal hernia.

Clinicians may wish to give advice to parents on image management, but this advice should be cautious. Bear in mind that until the clinician is involved, the parents are simply taking photographs of their child. One would not expect that the GMC guidance on making recordings ${ }^{5}$ of patients has any bearing on the parent who initiates the image. Considerations that a doctor would have to give to consent and confidentiality (and the notion of 'covert' recording) are not engaged. But if (and only if) the image is copied into the medical records, the usual legal duties will immediately thenceforth commence, although the constraints on doctors surrounding the creation of the image are inapplicable to the parent photographer.
If a clinician (or author) was to presume to advise the parent on image management, they would need to conform both to the law and their regulator's requirements. If doctors do wish to advise the parent on the management of parent-initiated images, it is strongly recommended they do so with the help of an academic or regulated lawyer specialising in communications law.

Nevertheless, should doctors aspire to instigate domiciliary image-taking, this would be clinically interesting, providing potential enhancement to conventional clinical assessment. If so, then they would need methodically to follow a trail, from the recommendation of correct camera angle/ lighting/definition of the area of interest, then leading to data protection in the device, anonymisation, data transfer and many another details, not least to ensure that the justification for the image creation is clearly articulated and that the many aspects of the GMC advice on recording are followed scrupulously. Furthermore, they need to ensure that in some way all reasonable steps have been taken to establish the identity of (1) the 'patient' being recorded, (2) the holder of parental responsibility and (3) any other persons in the room. Since this would be a clinical activity performed at clinical behest, there would be a standard of care to be upheld in the advice being given to the parents. Once again, a practitioner in communications law could collaborate with aspiring clinical initiators of domiciliary images to resolve what 'reasonable practice' would demand of the doctor in these circumstances. If this is to be done at all it must be done properly. A doctor who in good faith encourages a parent to take 'clinical' images of their child, without pondering the risks of being found to be acting below the reasonable standard of care in so doing, might regret that adventure.

Competing interests None declared.

Provenance and peer review Commissioned; externally peer reviewed.

C Author(s) (or their employer(s)) 2021. No commercial re-use. See rights and permissions. Published by BMJ.

\section{Check for updates}

To cite Wheeler R. Arch Dis Child

2021;106:1056-1057.

Received 11 February 2021

Revised 19 March 2021

Accepted 22 March 2021

Published Online First 14 April 2021

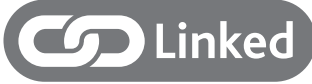

- http://dx.doi.org/10.1136/archdischild-2020321021

- http://dx.doi.org/10.1136/archdischild-2020321032 
Arch Dis Child 2021;106:1056-1057.

doi:10.1136/archdischild-2021-321753

ORCID iD

Robert Wheeler http://orcid.org/0000-0001-7242-6391

\section{REFERENCES}

1 Blackburn F, Butler M, Cheung CR. 'The paediatrician will hear you now': making virtual outpatient consultations work for children and young people. Arch Dis Child 2021;106:1041-3.

2 Motawea M, Digby M, Banks R, et al. Role of parentinitiated digital imaging in paediatric clinical practice. Arch Dis Child 2021:106:1044-6.

3 Devon Partnership NHST v Secretary of State for Health \& Social Care [2021] EWHC 101 (Admin).

4 Remote consultations. Remote consultations (over the phone, via video link or online) have increased. so when is it safe to prescribe without meeting a patient face to face? Available: https://www.gmc-uk.org/ethicalguidance/ethical-hub/remote-consultations [Accessed 8 Feb 2021].

5 The General Medical Council. Available: https:/l www.gmc-uk.org/ethical-guidance/ethical-guidancefor-doctors/making-and-using-visual-and-audiorecordings-of-patients/principles [Accessed 8 Feb 2021]. 